from medical professionals, Offit risks overegging his case for science. Precaution is sometimes a wise basis for policy-making. Vaccine damage through unforeseen effects does occasionally occur and may be severe. As Offit reminds us, one in every 100,000 patients suffered paralysis as a consequence of the US swine flu vaccination in 1976. Such rare episodes do not detract from the transformational effect of vaccines. But they remind us that not all concerns about vaccines can be dismissed as irrational.

Offit reports the personal testimonies of caring parents to good effect, but despairs in equal measure about their lack of scientific credibility and strong emotional appeal. One celebrity mother of an autistic child said, for example, "My science is Evan, and he's at home." Offit is anxious about patients actively participating in their own medical care using the Internet. For him, scientifically sound information online is drowned by poorly substantiated opinion.

Yet Offit's arguments falter when he uses vaccine controversies as his indicator of the presumed ignorance of science by the public. Communicating risk is notoriously tricky. Vaccine uptake needs to be sufficiently high to ensure protection of the population through 'herd immunity' - a persuasive task made all the more difficult when individual patients are urged to accept responsibility for their health and embrace the principle of choosing a hospital or consultant.

Autism's False Prophets encapsulates the fanciful belief among scientists, not supported by those who research science communication, that understanding the science will inevitably tip the scales of public opinion. This stance was demonstrated earlier this year in a letter to The Guardian newspaper from David Salisbury, director of immunization at the UK Department of Health. It draws attention to the ongoing UK public information campaign for adopting a vaccine intended to protect young women from human papilloma virus, the cause of most cervical cancer. The campaign, Salisbury wrote, aims to ensure that "parents and young women have all the information they need to consent to this important vaccine". Absent in such sentiments is a belief in the necessity for dialogue with the public, entirely different in tone and purpose from the mistaken compulsion of some well-intentioned vaccine enthusiasts to inject hard facts into empty vessels.

Jeff Thomas teaches science communication and health sciences in the Department of Life Sciences at The Open University, Milton Keynes, MK7 6AA, UK. He is co-editor of Practising Science Communication in the Information Age. e-mail:j.n.thomas@open.ac.uk

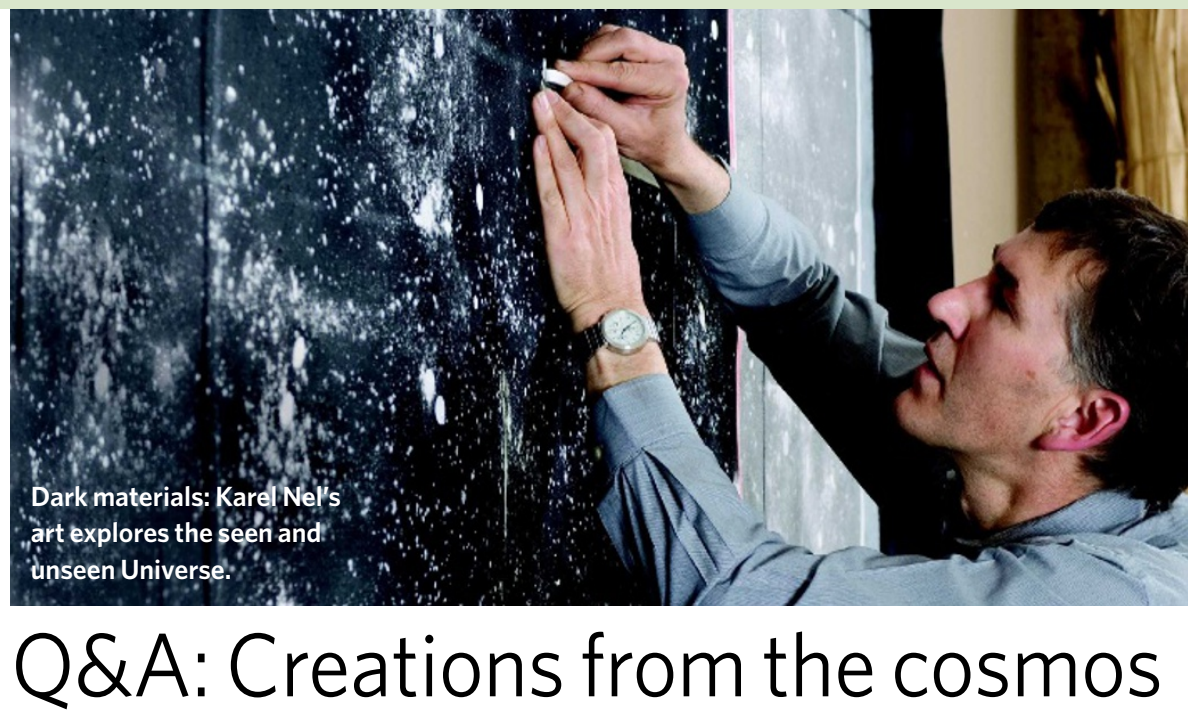

Artist Karel Nel works with astronomers from COSMOS, the global Cosmic Evolution Survey that is mapping galaxies and dark matter. Now exhibiting his work in London, he tells Nature how his view of the Universe has changed.

How did you get involved in astronomy?

Artists and scientists have questioned the nature of reality for centuries. Feeling the need to grasp contemporary scientific paradigms, I had worked for decades at the interface between these disciplines when I met Nick Scoville, leader of the COSMOS project. He invited me to be its resident artist. It was a very steep learning curve: I felt like an ant being taught compound interest by an economist.

\section{What does your work convey?}

My art investigates seen and unseen worlds. COSMOS looks back in deep time at patterns of galaxy formation and largescale structures, and from these, attempts to understand invisible dark energy and dark matter. I use metaphorical means to grasp these abstract ideas, as scientists often do. In my 20 exhibited works, I use mixed media including 540-million-year-old black carboniferous dust and white primordial salts from the oceans to present shimmering images of galaxies that emitted their light millions of years ago.

Have the scientists influenced your ideas? Yes - representing the Universe is not like painting a traditional landscape; there are invisible as well as visible aspects to convey. Scientists have developed codes to deal with cosmic phenomena, and my work captures the unstable nature of our perceptions of this distant, unknown terrain. In one piece, dotted lines echo the grids found in astronomy textbooks, but also refer to invisible characters, as used in comic books. In another, I evoke the 'blind spots' of telescopes with amorphous dark shapes.

\section{Did you influence the astronomers?}

Many of the astronomers focus on incremental, detailed information, so my broad outsider's perception rekindled the extraordinariness of their endeavour.

What was it like, visiting observatories?

At the summit of Mauna Kea, Hawaii, some of the world's most powerful telescopes are trained on the powder-black darkness, looking at complexity and eternity. It is awesome and desolate. Even the scientists fall silent in the face of that.

Interview by Jennifer Rohn, a researcher at University College London, Gower Street, London WC1E 6BT, UK, and editor of www.lablit.com. e-mail: jenny@lablit.com

\section{The Brilliance of Darkness}

Art First, 9 Cork Street, London W1S 3LL Until 9 October 2008

\title{
Enhance your life with Nature debates
}

Nature has picked two panels of experts in science, policy and ethics to debate research that is improving mental and physical abilities.

Enhancing the Brain: 13 October 2008 From intelligence to emotional tolerance, sleep requirements and memory power, how are developments in neuroscience affecting the individual and society? Panel: Barbara Sahakian, John Harris and Nick Bostrom.
Enhancing the Body: 10 November 2008 Studies of the human body are focusing on aspects such as speed, strength and healing or the tolerance of pain. But how will this science enhance the human body? Panel: Aubrey de Grey, Andy Miah and Kevin Warwick.

Nature debates will be held at 7pm at King Place, 90 York Way, London N1 9AG, UK See http://tinyurl.com/4zrh8v for more details. 